\title{
Bjerg, María, Lazos rotos. La inmigracion, el matrimonio y las emociones en la Argentina entre los siglos XIX y XX. Bernal, Universidad Nacional de Quilmes Editorial, 2019, 128 páginas.
}

\author{
Paula E. Román \\ paularoman87@gmail.com \\ Centro de Investigaciones Socio Históricas. Instituto \\ de Investigación en Humanidades y Ciencias Sociales. \\ CONICET - Universidad Nacional de La Plata, \\ Argentina
}

Recepción: 15 Marzo 2021

Aprobación: 20 Abril 2021

Publicación: 01 Julio 2021

Cita sugerida: Román, P. E. (2021). [Revisión del libro Lazos rotos. La inmigración, el matrimonio y las emociones en la Argentina entre los siglos XIX y $X X$ por M. Bjerg]. Trabajos y Comunicaciones, (54), e157. https://doi.org/10.24215/23468971e157

Estudiar procesos migratorios implica centrarse en un objeto de por sí esquivo. Las fuentes que registran a las poblaciones migrantes tienden a hacerlo con propósitos cuantitativos: censos, registros parroquiales y civiles conforman sus rastros más evidentes. Por esta razón, la propuesta de un abordaje cualitativo implica construir una mirada original que alumbre aquellas trayectorias con nuevas preguntas. Lazos rotos. La inmigración, el matrimonio y las emociones en la Argentina entre los siglos XIX y XX, de María Bjerg, logra este propósito articulando al menos tres dimensiones. Por un lado, se vale de los aportes conceptuales de la 
historia de las emociones, un campo de estudios que, aunque ha crecido de manera sostenida en los últimos años, registra un desarrollo aún incipiente en Argentina. Por otro, recurre a un fondo documental escasamente trabajado para el tema, las fuentes judiciales. Finalmente, articula en su mirada una perspectiva de género que le permite mostrar el carácter desigual en el tratamiento de los sujetos frente a la justicia, así como los matices de sus repertorios afectivos.

Un recorrido más amplio por otras obras de la autora exhibe un trabajo que, de manera sostenida, ha iluminado nuevas aristas del fenómeno. Sus libros se han ocupado de poblaciones migrantes no tradicionales, como los daneses; ha trabajado con la experiencia de migración en la infancia, con problemáticas ligadas a la vivienda, el espacio, las relaciones familiares y de género. En todos los casos, se destaca su impronta en torno a lo subjetivo que se nutre de fuentes orales, biografías, relatos de viaje y memorias. Por otra parte y en relación a Lazos rotos, los numerosos artículos académicos publicados en los últimos tiempos permiten desandar el camino por el que fue elaborando su aproximación metodológica al objeto, definida en este caso por el cruce entre migraciones, matrimonio y emociones. En consonancia con ello, el propósito del libro será abordar "los costos afectivos de la experiencia migratoria" (Bjerg; 2019). El recorte elegido toma las trayectorias de inmigrantes italianos y españoles, que llegan a la ciudad y la provincia de Buenos Aires, entre 1880 y 1914 , justificándose por el impacto que esos colectivos tuvieron en los dos territorios.

El libro se organiza en cuatro capítulos definidos por los delitos de bigamia, adulterio, lesiones y uxoricidio, ${ }^{1}$ estructura construida a fin de vislumbrar el punto de encuentro entre las distintas dimensiones de su objeto. El registro que ofrecen los expedientes judiciales le permite restituir la dinámica del conflicto a una trama historiográfica que, aunque nutrida, ha pasado por alto los problemas derivados de la adaptación en los y las inmigrantes. Muchos de estos estudios han representado una imagen romantizada que asume la fluidez de los intercambios epistolares, la espera paciente y el amor inquebrantable. Aunque todo eso existiera, la autora buscará contribuir a una imagen más realista, donde sus protagonistas fueron a menudo inmigrantes iletrados, con un acceso precario a la justicia, en trayectorias donde tuvo lugar la violencia, la frustración, el engaño y el olvido.

El trabajo organiza la exposición de casos de manera secuenciada, permitiendo una reconstrucción minuciosa de la experiencia del matrimonio en primera persona, surcada por la migración. Este tipo de acercamiento permite a la autora reparar en los guiones emocionales desplegados por los distintos actores en litigio. En este caso, la naturaleza afectiva de las estrategias y discursos llevados al estrado permite problematizar la supuesta racionalidad y asepsia en las instituciones, constituyendo esta una premisa que se buscará demostrar a todo lo largo del libro.

Luego de una introducción donde se definen los lineamientos metodológicos, el enfoque teórico y las fuentes mencionadas el primer capítulo, "La promesa, la espera y la traición", sigue tres expedientes por bigamia iniciados por las esposas a sus maridos. Tomados en conjunto, los casos muestran que, a pesar de las ataduras patriarcales y la inferioridad jurídica, las mujeres accionaron las herramientas de la justicia para denunciar a los bígamos, en reclamo por lo que entendían como una traición. Aquellas denuncias se centraron en el incumplimiento de su deber como esposos y varones proveedores, es decir, se expresaron en el marco de las relaciones de género tradicionales. Sin embargo, al recuperar el registro emocional de aquellas mujeres en torno a los sentimientos de humillación, vergüenza y dolor, la autora complejiza la mirada, postulando las emociones como configuraciones históricas que permearon y motorizaron las denuncias.

En su defensa, los bígamos alegaron la rebeldía de sus esposas desobedientes que se habían negado a migrar con ellos en el primer momento, hasta la creencia de que estaban muertas, eximiéndolos de las obligaciones conyugales. Sin embargo, el peso del rumor en la comunidad (a una y otra orilla del mar) operaba regulando las "conductas desviadas", facilitando los mecanismos por los cuales se constataba la infidelidad. Si la Buenos Aires hiperpoblada parecía prometer el anonimato, la autora muestra que "en el escenario estrecho de la vida cotidiana donde todos se conocen” (Bjerg; 2019) el rumor triunfaba, accionándose los mecanismos de control social entre compatriotas. 
En parte anticipándose a los demás, este capítulo aborda ampliamente la experiencia migratoria con algunas referencias que acabarán por iluminar todos los casos del libro. La concepción de la migración como factor disruptivo del orden familiar resulta fundamental para entender la trama conflictiva en la que se inscribieron aquellos matrimonios naufragantes plasmados en los expedientes. El trabajo de la espera, la distancia e incomunicación conspiraban contra el vínculo matrimonial, desdibujando la promesa de un futuro armonioso. "Hacer la América" supuso en verdad el complejo aprendizaje de lidiar con la desilusión y la frustración, en un contraste entre expectativas y realidad, a menudo surcado por la miseria. La autora muestra que los acuerdos migratorios debían renegociarse de manera permanente y que, muchas veces, lo que comenzaba como una estrategia del grupo familiar, pasaba a ser la trayectoria de un individuo que podía olvidar los compromisos.

El segundo capítulo, "quebrantar los deberes sagrados", recorre cuatro expedientes sobre adulterio femenino que son organizados en torno a 3 núcleos de emociones: venganza asociada a la ira, vergüenza y compasión. Los títulos remiten a los sentimientos que los varones expresaron en las declaraciones a la justicia, en relación a sus esposas adúlteras. El núcleo de las denuncias sostenía que las mujeres faltaban al "sagrado mandato del matrimonio". Sin embargo, al indagar más profundo en las trayectorias de aquellas migrantes, la autora logra reconstruir la dinámica compleja de un vínculo desgarrado por la migración. Los casos analizados muestran que muchas optaron por volver a emparejarse para salir de la miseria, constituyendo un nuevo núcleo familiar que garantizara la supervivencia de los hijos e hijas. Por añadidura, la perspectiva de historia de las emociones exhibe la erosión de los lazos, animada por el paso del tiempo y la distancia, tanto como la aspiración genuina de reconstruir la propia vida junto a otra persona.

La infidelidad femenina operaba dañando el honor del esposo y, a través de él, el de toda su familia pues significaba una mujer díscola que el núcleo no podía gobernar, invirtiendo las reglas de género. El andamiaje familiar se articulaba detrás de los intereses patriarcales controlando colectivamente aquellas conductas en un abanico que iba desde el cultivo del pudor femenino hasta la violencia física y el asesinato. En esta clave, la autora muestra que las familias de los varones migrantes que quedaban en la península procuraban un doble mecanismo tanto de sostén y cuidado como de control y sanción, siguiendo de cerca los comportamientos de "sus mujeres". No obstante, el caso de una esposa que quedó bajo la guarda del cuñado, exhibe las fisuras en el sostenimiento de aquella estrategia, en tanto este acabó juntándose con su protegida.

En las demandas analizadas, Bjerg muestra que los varones esgrimían su derecho patriarcal a la obediencia de las esposas, a pesar de años de abandono, despojos y violencia, o simplemente cuando estas ya no los querían. Nuevamente, las mujeres esgrimieron sus defensas allí donde tenían posibilidad de ser oídas: retomaron la semántica del derecho patriarcal, aduciendo la falla del rol proveedor y deberes de esposo. En cualquier caso, los núcleos emocionales de la ira y el resentimiento se articularon en la proyección de estrategias para castigar a las esposas, que acabaron cumpliendo algún tipo de pena.

El tercer capítulo, "Cuerpos indóciles y odios cotidianos", centra su atención en cuatro casos que tienen a las mujeres como víctimas de lesiones graves provocadas por sus maridos. La ira es la emoción protagonista en los expedientes siendo invocada por los acusados y, en ocasiones, también por sus defensores.

A lo largo de este capítulo la autora reflexiona sobre la violencia conyugal y su estrecha vinculación con la pobreza en las trayectorias migrantes. La diferenciación del capítulo en dos subtítulos que ponen énfasis en la miseria y el dinero, así lo reflejan. Con el fin de encuadrar y dar sentido a los procesos judiciales, también se aborda el modo en que la prensa informaba sobre la violencia doméstica, revelando un margen que iba de la tolerancia a la condena moral. En todos los casos, los expedientes muestran la cruenta violencia ejercida por los maridos sobre aquellos cuerpos femeninos que aparecen como objeto del abuso y el dominio del agresor. Los acusados y su defensa justificaban la ira apoyándose en el derecho patriarcal de la obediencia que sus esposas les debían. Las caracterizaron como nerviosas, contestadoras y gruñonas, justificando incluso en un caso que estas características operaron "quitándole los hábitos de trabajo" al marido. Por su parte ellas sostuvieron que los maridos bebían y despilfarraban el magro dinero que hacían trabajando como planchadoras o sirvientas, 
razón por la cual buscaron alternativas que iban desde la fuga del hogar al adulterio. Al optar por cualquiera de estas opciones, sin embargo, caían fuera de la ley y los esposos tenían herramientas para perseguirlas. Así, el dinero que las mujeres ganaban de manera independiente aparece como objeto de disputa masculina, aspecto sobre el que la autora se detiene para analizarlo en su variable moral. Esta mirada le permitirá mostrar que la ira de los esposos no se fundaba en el dinero en sí, como en la inversión de los roles de género.

Finalmente, este capítulo aporta una valiosa reflexión en torno al universo cultural de los y las migrantes en su acceso a la Justicia. La autora señala que, en ocasiones, las migrantes recurrieron a la policía sin sospechar los procedimientos que se iniciaban después de efectuarse la denuncia. A menudo, el encierro del marido por lesiones implicaba quedarse sin el sustento familiar, exhibiendo el estrecho margen de opciones entre la miseria y los golpes. Nuevamente y en todos los casos, se indaga el conjunto de repertorios emocionales que imputados e injuriadas pusieron a disposición mediando su acceso a lo que creían justo para sí, y las implicancias que esto tuvo en la Justicia.

El cuarto y último capítulo indaga dos uxoricidios que fueron relacionados con "la pasión de los celos". Siguiendo la modalidad del capítulo tres, la autora ofrece una aproximación al tratamiento que los periódicos dieron en estos casos donde la variable explicativa fue el "amor". Arguyéndose que la pasión podía incurrir en la locura se presentaron casos donde los uxoricidas eran en parte "comprendidos" como enamorados sin remedio. Del mismo modo, los agentes del sistema judicial, aun con matices, reprobaron las conductas irregulares de las esposas, incluso después de muertas, entendiendo que el adulterio reiterado debía haberles anticipado a la vergüenza y humillación que sufrirían sus maridos y por tanto, el fatal desenlace.

En otro caso, la "tristeza" cumple un rol relevante en el argumento del uxoricida, quien busca posicionarse como la "verdadera víctima", afectada por el adulterio de su esposa. De manera notable, el hombre acaba por ser absuelto, tras desplegar un guión narrativo en torno al arrepentimiento. Este caso es tal vez el más contundente en relación a los modos en que ciertas performances emotivas podían afectar los procesos penales, contemplando mayormente a los varones para justificar sus acciones y reducir la pena.

Entre emociones, titulares y expedientes, las historias migrantes que María Bjerg rescata del olvido iluminan una gramática de género que exhibe las dolorosas consecuencias que enfrentaron aquellas mujeres al desafiar la autoridad del marido o "lacerar su honor". En esta clave, si bien no se consigna especialmente como herramienta teórica, el concepto de patriarcado asume una dimensión relevante en el trabajo, recogiendo peso propio en el desarrollo. La justicia reflejada en las sentencias aparece, así, como expresión de un derecho patriarcal que respalda la autoridad masculina y reproduce la subordinación femenina. Por último, su lectura atenta de los guiones emocionales, le permite mostrar que las emociones no sólo formaban parte de la trayectoria subjetiva de los y las migrantes, sino que constituyeron una parte integral en la semántica de las instituciones judiciales.

Lazos rotos, en suma, no sólo recoge una mirada renovada sobre las migraciones trasnacionales de fines de siglo XIX y principios del XX, sino que contribuye haciendo un aporte sustancial a la incipiente trayectoria nacional en el campo de los estudios sobre emociones, así como en la historia social de la justicia a través del prisma de género.

\section{Notas}

1 La noción de uxoricidio designaba el homicidio o asesinato de la esposa por parte del marido. 